\title{
Metro line implementation in a European city
}

\author{
N. M. Gomes Rocha \\ PROEC-Projectos, Estudos e Construções Lda., Braga, Portugal
}

\begin{abstract}
The train is the earliest form of mass transport, and with technological evolution it has become far less of a polluter. Green and sustainable transportation is essential for every region for social and economic growth.

This paper will analyse specificities of a European urban rail network. Offer/demand disequilibrium is identified and potential solutions are presented. Because the geographical area is vast and data is dissipated, it is essential to select the most accurate information available.

A first step is to determine disequilibrium between existing capacity and current rail transport demand. Existing capacity is total daily number of "passengers" transported in each rail network zone. Current transport demand is total number of "citizens" that need rail transport for daily displacements in each zone.

Current rail transport demand estimation is based on regression analyse tools applied to Local Transport Authority annual mobility reports. Demand is also estimated for new line entrance in service year, plus ten, twenty and thirty years.

These long term previsions are essential to analyse offer/demand evolution process with reversed impacts in land-use politics.

Different transport options are going to be analysed. Its economical and technical viability will be considered to support a final solution.

This paper will start with a city and existing transport network briefing. This will be followed by a service characterization. Existing capacity is determined to establish a workable level. Current transport demand and its characteristics will precede demand variation. Main factors influencing these variables are presented. Disequilibrium and potential solutions are going to be evaluated before conclusion with economical analysis.

Keywords: urban rail transport, offer/demand estimation process, transport projects economical analyse, existing capacity, current demand.
\end{abstract}




\section{Introduction}

This paper reflects part of a consultation project final report for a European city Municipality. The city name and other critical facts are going to be disclaimed in order to complete existing confidentiality agreements. Presented scenario reflects a relative reality. Inter-relation variables are maintained.

Disequilibrium between existing capacity and current demand for rail transport is determined.

Existing capacity is total daily number of "passengers" transported in each section of rail network. It is determined by relating "passengers/public transport stop/day" with the "number of public transport stops/section". A section is part of a region defined by common characteristics according to available data.

Current rail transport demand is total number of "citizens" that need rail transport for daily displacements. A section requires transport improvements when demand is higher than existing capacity.

City and public transport network brief is presented in section 2 . It includes demographic and economical data and different transport modes in service at study area. This will be followed, in section 3, by service characterization. Number of public transport stops, number of inhabitants/stop and number of stops $/ \mathrm{km}^{2}$ are presented. In this same section existing transport capacity is determined.

Project economical viability conclusion, in section 6 , is preceded by current transport demand, evolution process and disequilibrium quantification, section 4, and potential solutions analysis with demand projections, in section 5.

\section{Scenario brief}

\subsection{City}

The city had suffered an intense modification in the last 20 year's caused by big events organization that created the opportunity to be re-structured. It is a city of passions, namely architectural, with an intensive touristic industry.

It receives 5 million tourists each year that stay for two nights on average. Considering $100 €$ daily expenses/tourist, it transacts $1000 €$ millions/year, and still with a growing capacity.

There are more than 1.5 million inhabitants inside a $101 \mathrm{~km}^{2}$ urban area and another 3.5 million within $50 / 60 \mathrm{~km}$ city limits. Population density is around 16.000 inhabitants $/ \mathrm{km}^{2}$. Urban area is divided in 10 districts.

Only $48 \%$ of population is male. Until the mid 80 's population growth had impressive rates but in the last 10/20 years it become stable.

City can be divided in three segments: touristic, residential and commercial. Tourism is concentrated in very specific points, while residential areas are concentrated around city centre that is mainly commercial. Main university is located outside residential area to North/East. Sport infrastructures are close to university area. Cultural infrastructures are dispersed in city but concentrated in specific areas. The biggest green area is concentrated in the South/East. 


\subsection{Public transport network}

The transportation network is totally integrated from a user point of view. With the same ticket it is possible to travel in all transports modes. There are hundreds of connection points.

Network is constituted of a multitude of urban, interurban and touristic buses, metro, train, tram, one funicular and two cable cars.

The bus network has numerous lines and stops. Metro network is constituted of 6 lines.

Train service is divided in two parts. Medium distance trains, connecting various regional points to city centre. It includes 6 lines. Small distance trains, connecting distances limited to city outskirts. It is based in 12 lines.

The tram was recently introduced. Its strategic lines location quickly imposed it in population mobility habits. It extends for 5 lines.

A funicular service is available despite passengers reduced number. However, it has geographical importance by connecting city centre to main green area. It offers 1 line.

Finally, there are two cable cars without profound impacts.

In this presentation it is used the concept "stop" as passengers reception and distribution point, distinguished from the concept "station" that could include at least 2 stops of different lines and different transport modes at interconnection points.

To plan and implement a new rail service is this study's main objective.

\section{Rail network}

In table 1 is possible to verify number of passengers/annum and its impact factor in rail transport users' mobility.

Table 1: $\quad$ Number of passengers/rail transport mode/annum.

\begin{tabular}{|c|c|c|}
\hline Transport mode & $\begin{array}{c}\text { Annual Passengers Volume (in } \\
\text { Millions) }\end{array}$ & Impact factor \\
\hline Metro & 370 & 0.62 \\
\hline Long distance train & 125 & 0.21 \\
\hline Short distance train & 80 & 0.14 \\
\hline Tram & 15 & 0.03 \\
\hline Funicular & 0,5 & 0.00 \\
\hline Total & 591 & \\
\hline
\end{tabular}

\subsection{Service characterization}

More than 13 million displacements occur daily in the metropolitan area. Displacement is all types of movement done by any resident of an area, from one point to another inside that area.

An average 3.4 displacements/day/inhabitant occurs. However, this includes "transport professionals", like messengers, transporters, etc. "Transport 
professionals" have an average 17.0 displacements/day. So it means that "general population" make 3.1 displacements.

Almost 3 million displacements are obligatory mobility, 4 million are non obligatory mobility and 5.5 million are coming home mobility.

Table 2: $\quad$ Number of stops/transport mode and Efficiency factor.

\begin{tabular}{|c|c|c|}
\hline Transport mode & Number of stops & Efficiency factor \\
\hline Metro & 123 & 1.77 \\
\hline Long distance train & 106 & 0.70 \\
\hline Short distance train & 75 & 0.65 \\
\hline Tram & 47 & 0.23 \\
\hline Funicular & 2 & 0.00 \\
\hline Total & 353 & \\
\hline
\end{tabular}

Service characterization will include total stops, in table 2, inhabitants/stop and stops $/ \mathrm{km}^{2}$, in table 3 .

For this city and according to local mobility patterns, most effective rail transport mode is metro and with highest potential grow is tram.

Table 3: Number of inhabitants/stop and number of stops $/ \mathrm{km}^{2}$.

\begin{tabular}{|c|c|}
\hline Factor & Value \\
\hline Number of inhabitants/stop & 10.481 \\
\hline Number of stops $/ \mathrm{km}^{2}$ & 1,5 \\
\hline
\end{tabular}

Number of passengers/stop/day for metro is over 8.000 while for long and short distance trains are around 3.000. Tram has an average 1.000 passengers/stop/day.

\subsection{Existing capacity}

Existing capacity (number of passengers/day) is sum of existing capacity in each section. In table 4 is possible to see different sections behaviour.

Table 4: $\quad$ Existing capacity.

\begin{tabular}{|c|c|c|c|c|}
\hline Section & Description & Inhabitants/stop & Stops/km $^{2}$ & $\begin{array}{c}\text { Existing } \\
\text { capacity }\end{array}$ \\
\hline 1 & Touristic/commercial & 8.561 & 2.9 & 83.206 \\
\hline 2 & Residential/commercial & 8.898 & 3.9 & 211.101 \\
\hline 3 & Residential & 26.686 & 1.1 & 34.368 \\
\hline 4 & Residential/green Area & 21.240 & 0.7 & 65.718 \\
\hline 5 & Residential & 13.749 & 1.5 & 91.061 \\
\hline 6 & Residential/low tech jobs & 12.964 & 1.7 & 82.847 \\
\hline 7 & Residential/high tech jobs & 6.907 & 3.0 & 156.891 \\
\hline 8 & Low tech jobs/services & 12.251 & 0.7 & 95.042 \\
\hline 9 & Residential/university & 5.899 & 2.3 & 46.491 \\
\hline 10 & Residential & 10.405 & 0.7 & 45.932 \\
\hline
\end{tabular}

Rail network has capacity to process 912.657 passengers/day. 


\section{Evolution process}

\subsection{Current transport demand}

Current transport demand is obligatory, non obligatory, coming home and touristic mobility demands sum.

To structure available data, obligatory and coming home mobility is subdivided in internal and external. Touristic mobility is subdivided into hotel offers and touristic places. In table 5, the city current rail transport demand is presented.

Table 5: $\quad$ Current transport demand/mobility type.

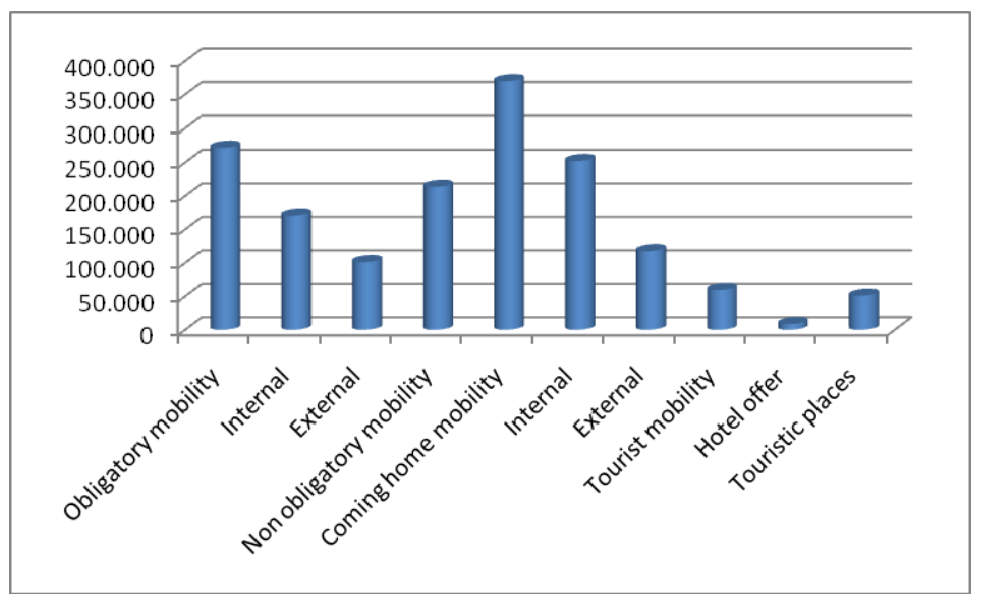

Current transport demand in the city is 914.614 passengers/day. In table 6 is presented disequilibrium in each section.

Table 6: Current demand/section.

\begin{tabular}{|c|c|c|}
\hline Section & Current Demand & $\begin{array}{c}\text { Disequilibrium } \\
\text { offer/demand }\end{array}$ \\
\hline 1 & 82.271 & 935 \\
\hline 2 & 252.787 & -41.686 \\
\hline 3 & 67.759 & -33.391 \\
\hline 4 & 61.665 & 4.053 \\
\hline 5 & 61.101 & 29.960 \\
\hline 6 & 60.494 & 22.353 \\
\hline 7 & 111.864 & 45.027 \\
\hline 8 & 81.137 & 13.905 \\
\hline 9 & 46.695 & -204 \\
\hline 10 & 88.841 & -42.909 \\
\hline
\end{tabular}


Sections 2, 3 and 10 are already requiring improvements in rail transport offer. However sections 1, 4 and 9 have a balanced offer/demand; in new line entrance in service year that situation will be different.

\subsection{Entrance in service demand}

Future demand it affected by different factors. For each mobility type, obligatory, non obligatory, coming home and touristic, were defined different factors according to local land use instruments and politics. Impact in each section is variable according to its characteristics. In table 7 is possible to find demand in entrance in service year.

Table 7: $\quad$ Entrance in service year demand/section.

\begin{tabular}{|c|c|}
\hline Section & Current Demand \\
\hline 1 & 86.632 \\
\hline 2 & 257.276 \\
\hline 3 & 69.387 \\
\hline 4 & 63.304 \\
\hline 5 & 63.668 \\
\hline 6 & 63.101 \\
\hline 7 & 117.284 \\
\hline 8 & 84.311 \\
\hline 9 & 48.500 \\
\hline 10 & 91.396 \\
\hline
\end{tabular}

Estimated demand for entrance in service year is 944.859 passengers/day. Section 1 has a balanced situation, but it is highly probable that in future that situation changes. This section is a city main touristic attraction point. There are visible system inabilities when this demand type increases. This is reflected in overcrowded stops and trains. Vehicles frequency increasing does not solve this situation.

In section 2, disequilibrium between actual offer and demand is clear. According to section characteristics, it has a stable demand during the year, and in peak hour it is almost an adventure to start or arrive from this section.

Section 3 has a deficiency in rail transport infrastructure with impacts in traffic fluidity and atmospheric pollution.

Sections 4, 5, 6, 7 and 8, despite their specificities, already have capacity to accommodate demand increasing.

Section 9 has very specific characteristics. Mobility is influenced by two facts that attract giant masses. University is responsible for daily displacement of thousands that start and arrive from there in very specific hours. During those hours passengers' concentration in stops and trains is high. A football stadium is located in this section, and in match days congestion is visible.

Section 10, population does not consider rail transport as an option. There is not visible accumulation of passengers in stops or trains. This decision is understandable considering service available. If there is a credible alternative, certainly there is enough market for it. Mobility type is stable during the day and year. 


\section{Solutions}

\subsection{Technical evaluation}

Solution to disequilibrium is a new rail line. The main options are a metro or a tram line. In table 8 is possible to find generic characteristics of these two solutions.

Table 8: $\quad$ Metro and tram characteristics.

\begin{tabular}{|c|c|c|}
\hline Characteristic & Metro & Tram \\
\hline Passenger capacity & 650 & 200 \\
\hline Working hours & 20 & 20 \\
\hline Frequency (in min.) & & \\
\hline 5am - 7am & 8 & 14 \\
\hline 7am - 9pm & 4 & 5 \\
\hline 9pm - 1am & 8 & 14 \\
\hline Construction costs (in €Millions/km) & & \\
\hline line & 60 & 10 \\
\hline station & 120 & 35 \\
\hline Exploration costs (€/km completed) & 9.2 & 19.0 \\
\hline
\end{tabular}

For landscape impact, the metro is better than the tram. The tram is a surface transport so it implicates a higher landscape change while metro as a subterranean transport has a lower landscape impact.

In analysing trip quality, it is clear that the tram is better than the metro. City landscape is considerably better than tunnel landscape. This negative impact of metro could be minimized by "station of art". This concept supposes that metro stations are not only places of passengers' reception and distribution but could be a place to expose art, like sculptures, or cultural events.

Total environmental impact is similar to both solutions. Pollution levels are similar. The metro, because of its higher passenger capacity, has lower emissions/passenger rates.

In costs analysis it is verified that the metro has higher construction costs, but tram exploration costs are higher. A possible combination of both services represents a lower efficiency.

Potential places for solutions implantation geographical analysis concluded technical impossibilities for Tram. Reduced street length and high traffic impacts in some sections does not permit Tram construction.

\subsection{Final solution}

The final solution is a metro line with a origin in section 1 that is separated in section 2 with a destination arriving in section 9 through section 3 and another arriving in section 10. In table 9 is a summary for this solution. 
Table 9: $\quad$ Final solution generic characteristics.

\begin{tabular}{|c|c|}
\hline Characteristic & Value \\
\hline Total number of stations & 21 \\
\hline Number of stations (Common) & 9 \\
\hline Number of stations (Section 9) & 8 \\
\hline Number of stations (Section 10) & 4 \\
\hline Total length (in meters) & 14150 \\
\hline Highest distance between stations (in meters) & 1200 \\
\hline Lowest distance between stations (in meters) & 500 \\
\hline Tunnel diameter for uneven platforms (in meters) & 12 \\
\hline Average distance to surface (in meters) & 35 \\
\hline Gauge (in mm) & 1435 \\
\hline
\end{tabular}

\subsubsection{Metro line demand evolution}

In table 10 is presented the demand evolution per station.

Table 10: Demand evolution/station.

\begin{tabular}{|c|c|c|c|}
\hline Station & $\begin{array}{c}\text { Service entrance } \\
\text { year }\end{array}$ & $\begin{array}{c}20 \text { years } \\
\text { later }\end{array}$ & $\begin{array}{c}40 \text { years } \\
\text { later }\end{array}$ \\
\hline 1 & 6.372 & 6.420 & 6.466 \\
\hline 2 & 6.439 & 6.515 & 6.575 \\
\hline 3 & 7.477 & 7.554 & 7.614 \\
\hline 4 & 7.160 & 7.406 & 7.480 \\
\hline 5 & 8.002 & 8.040 & 8.103 \\
\hline 6 & 7.737 & 7.822 & 7.917 \\
\hline 7 & 6.320 & 6.412 & 6.505 \\
\hline 8 & 6.666 & 6.720 & 6.810 \\
\hline 9 & 7.530 & 7.625 & 7.711 \\
\hline 10 & 8.135 & 8.207 & 8.298 \\
\hline 11 & 8.195 & 8.259 & 8.312 \\
\hline 12 & 8.907 & 9.009 & 9.095 \\
\hline 13 & 9.003 & 9.115 & 9.207 \\
\hline 14 & 9.260 & 9.325 & 9.407 \\
\hline 15 & 9.387 & 9.461 & 9.508 \\
\hline 16 & 9.359 & 9.436 & 9.535 \\
\hline 17 & 9.201 & 9.283 & 9.345 \\
\hline 18 & 8.402 & 8.506 & 8.559 \\
\hline 19 & 8.193 & 8.266 & 8.318 \\
\hline 20 & 8.200 & 8.291 & 8.352 \\
\hline 21 & 8.173 & 8.213 & 8.274 \\
\hline Total & 168.118 & 169.885 & 171.391 \\
\hline
\end{tabular}




\section{Conclusion}

A cost/benefit was performed for a 50 year project life. Based on demand/stop, ticket price/displacement/passenger, construction, financial and exploration costs it was determined that investment is viable. Exploration costs include vehicles acquisition and conservation cost. It also includes direct exploration costs such as: workers salaries or electricity. At the end of project life a total liquid profit of over $€ 68$ million is expected.

In table 11 the cost/benefit analyse is summarized.

Table 11: Cost/benefit analyse summary.

\begin{tabular}{|c|c|c|c|}
\hline Variable & Value & $\begin{array}{l}\text { Variable } \\
\end{array}$ & Value \\
\hline $\begin{array}{l}\text { Price/displacement/passenger } \\
\text { (in } € \text { ) }\end{array}$ & & $\begin{array}{c}\text { Annual income (in } \\
€)\end{array}$ & \\
\hline Current & 0.7 & (Potential) Current & 42.184 .583 \\
\hline Service entrance year & 0.85 & $\begin{array}{c}\text { Service entrance } \\
\text { year }\end{array}$ & 52.158 .610 \\
\hline 20 years later & 1.55 & 20 years later & 96.112 .439 \\
\hline 40 years later & 2.95 & 40 years later & 184.545 .259 \\
\hline Construction cost (in Million $€$ ) & & $\begin{array}{c}\text { Annualized } \\
\text { construction cost } \\
\text { (in Million } € \text { ) }\end{array}$ & \\
\hline Total cost in station & 210 & Total cost in station & 4.2 \\
\hline Total cost in line & 852 & Total cost in line & 17.0 \\
\hline Financial costs (in Million $€$ ) & & $\begin{array}{c}\text { Annualized } \\
\text { financial cost (in } \\
\text { Million } € \text { ) }\end{array}$ & \\
\hline Financial costs & 531 & Financial costs & 10.6 \\
\hline $\begin{array}{l}\text { Exploration costs (in } € / \mathrm{km} \\
\text { completed) }\end{array}$ & & $\begin{array}{l}\text { Annual Exploration } \\
\text { cost (in } € \text { ) }\end{array}$ & \\
\hline Current & 7.8 & (Potential) Current & 10.308 .987 \\
\hline Service entrance year & 15 & $\begin{array}{c}\text { Service entrance } \\
\text { year }\end{array}$ & 20.135 .955 \\
\hline 20 years later & 46 & 20 years later & 62.465 .516 \\
\hline 40 years later & 110 & 40 years later & 150.514 .320 \\
\hline Number of trains & & $\begin{array}{l}\text { Annual Liquid } \\
\text { result (in } € \text { ) }\end{array}$ & \\
\hline Current & 255 & Current & -31.800 .000 \\
\hline Service entrance year & 259 & $\begin{array}{c}\text { Service entrance } \\
\text { year }\end{array}$ & 162.655 \\
\hline 20 years later & 262 & 20 years later & 1.786 .923 \\
\hline 40 years later & 264 & 40 years later & 2.170 .939 \\
\hline
\end{tabular}




\section{References}

This paper is based in a final report of a consultation project. In the development of such a project numerous literature was used. Here is a small list of publications the author considers important:

[1] Hutchinson, B. G., Principles of urban transport systems planning, Scripta Book Company, 1974.

[2] Rodrigue, J.-P., Comtois, C., Slack, The geography of transport systems, Routledge, 2006.

[3] Steenbrink, P.A. Optimization of transport networks, A Wiley-Interscience Publication, 1974.

[4] Vuhic, V., Urban Public Transportation, Prentice Hill, 1981

[5] White, P.R., Planning for public transport, Hutchinson \& Co (publishers) Lda, 1976. 